\title{
Developmental and Clinical Aspects of Surfactant-Related Neonatal Lung Disease
}

Proceedings of the 18th International Workshop on

Surfactant Replacement, Prague, June 5-7, 2003

\author{
Guest Editors \\ R. Plavka, Prague \\ T. Curstedt, Stockholm \\ H.L. Halliday, Belfast \\ B. Robertson, Stockholm \\ O.D. Saugstad, Oslo \\ C.P. Speer, Würzburg
}

